DOI: $10.1590 / 1809-6891 v 15 \mathrm{i} 22238$

\title{
EFEITO DO FOTOPERÍODO SOBRE A COMPOSIÇÃO DO FILÉ DE JUVENIS DE TILÁPIA DO NILO
}

\author{
Galileu Crovatto Veras ${ }^{1}$, Luis David Solis Murgas ${ }^{2}$, Marcio Gilberto Zangeronimo ${ }^{2}$,

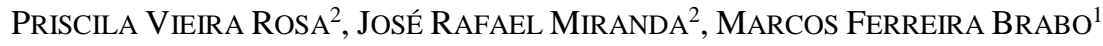 \\ ${ }^{1}$ Professores Doutores da Universidade Federal do Pará, Bragança, PA, Brasil - galileu@ufpa.br \\ ${ }^{2}$ Professores Doutores da Universidade Federal de Lavras, Lavras, MG, Brasil.
}

\begin{abstract}
Com este estudo objetivou-se avaliar o efeito do fotoperíodo sobre a composição centesimal de filés de juvenis de tilápia do Nilo. Utilizou-se um delineamento inteiramente casualizado com cinco tratamentos (0L:24E; 6L:18E; 12L:12E; 18L:6E; 24L:0E) e quatro repetições. Foram utilizados 160 alevinos de tilápia, distribuídos em 20 aquários $(20 \mathrm{~L})$ em sistema de recirculação, temperatura controlada em $27^{\circ} \mathrm{C}$ e densidade de oito peixes por aquário. Os peixes foram alimentados duas vezes ao dia, com ração comercial extrusada contendo $40 \%$ de proteína bruta. Ao final de 75 dias, amostras do filé foram coletadas e armazenadas em freezer $\left(-80{ }^{\circ} \mathrm{C}\right)$ para posteriores análises
\end{abstract}

da composição bromatológica. Não houve efeito dos diferentes fotoperíodos sobre a umidade e cinzas do filé $(\mathrm{P}>0,05)$. Por outro lado, os peixes sob fotoperíodo de 18L:6E apresentaram maior quantidade de proteína e retenção desta no filé, assim como menor quantidade de gordura e retenção de lipídeo $(\mathrm{P}<0,05)$. Portanto, pode-se concluir que o fotoperíodo pode alterar a composição corporal de alevinos de tilápia do Nilo, sendo que e o fotoperíodo de 18L:6E contribui para o aumento da concentração de proteína bruta e uma menor deposição de gordura no filé.

PALAVRAS-CHAVE: composição centesimal, Oreochromis niloticus, retenção de nutrientes.

\section{EFFECT OF PHOTOPERIOD ON FILET COMPOSITION OF NILE TILAPIA JUVENILES}

\section{ABSTRACT}

This study aimed to evaluate the effect of the photoperiod on the fillet composition of Nile tilapia juveniles. We employed a completely randomized design with five treatments (0L:24D, 6L:18D, 12L:12D, 18L:6D, 24L:0D) and four replications. We used 160 Nile tilapia juveniles, distributed in 20 tanks containing 20 liters of water, in a recirculation systems, at controlled temperature of $27{ }^{\circ} \mathrm{C}$ and density of eight fish per tank. Fish were fed twice a day with commercial extruded feed containing $40 \%$ crude protein. Samples of the fillet at the end of 75 days were collected and stored in a freezer at $-80{ }^{\circ} \mathrm{C}$ for subsequent analysis of chemical composition. There was no effect of photoperiod on moisture and ash content of the fillet (P>0.05). The period 18L:6D showed higher amounts of protein in the fillet, as well as lower amounts of fat $(\mathrm{P}<0.05)$. Therefore, it can be concluded that the photoperiod can alter Nile tilapia body composition, and the photoperiod 18L:6D contributed to the higher concentration of crude protein and lower fat deposition in Nile tilapia fillets.

KEYWORDS: composition, nutrient retention, Oreochromis niloticus. 


\section{INTRODUÇÃO}

A tilápia do Nilo (Oreochromis niloticus) é uma espécie de peixe de crescente interesse econômico e de destaque para a aquicultura brasileira em razão do seu elevado potencial de produção, apresentando rendimentos de filé variando de $25 \%$ a $42 \%{ }^{1,2}$. A espécie apresenta alta rusticidade, rápido crescimento, menor tempo para atingir o tamanho comercial e boa aceitação no mercado consumidor devido à carne de ótima qualidade que não apresenta espinhas na forma de "Y" no filé, 3 .

O rendimento em filé de um peixe depende do peso, sexo, composição corporal, características anatômicas (relação cabeça/corpo), grau de mecanização no processo, método de filetagem e destreza do operador ${ }^{1}$. Quanto ao aspecto nutricional, é importante se conhecer a composição química do pescado para que o consumo seja estimulado, possibilitando a competição com outras fontes proteicas largamente utilizadas como a carne bovina, suína e de aves ${ }^{4}$. O músculo do pescado contém entre 60 e $85 \%$ de umidade, $20 \%$ de proteínas, 1 a $2 \%$ de cinzas e 0,6 a 3,6\% de lipídios. Este último componente apresenta uma variação mais significativa dependendo da espécie, sexo, idade e tipo de músculo, sendo a carne dorsal com menor quantidade lipídica do que a carne abdominal $^{5}$.

O fotoperíodo, além de estimular o crescimento, pode levar a alterações na composição centesimal do pescado ${ }^{6}$, uma vez que influencia o desenvolvimento e a sobrevivência em diferentes fases ontogênicas. Além disso, o fotoperíodo influencia tanto na estratégia alimentar como no estímulo das atividades metabólicas de vários peixes $^{7,}{ }^{8}$. Para algumas espécies, dias ou fotoperíodos longos podem modificar indiretamente o crescimento, seja pela indução ao aumento do consumo de ração, desenvolvimento da massa muscular devido à maior atividade locomotora dos animais ${ }^{9-12}$, melhor eficiência na utilização dos nutrientes ${ }^{6,13}$ e / ou devido ao redirecionamento da energia proveniente da maturação gonadal para o crescimento somático ${ }^{9,14}$, 15 .

No entanto, poucas informações estão disponíveis na literatura sobre os efeitos do fotoperíodo na composição bromatológica de peixes. Assim, com a execução deste trabalho objetivou-se avaliar a interferência do fotoperíodo na composição centesimal do filé de juvenis de tilápia do Nilo.

\section{MATERIAL E MÉTODOS}

O experimento foi realizado no Laboratório de Fotoperíodo de Peixes do Setor de Fisiologia e Farmacologia do Departamento de Medicina Veterinária da Universidade Federal de Lavras, MG, de março a abril de 2010, por um período de 75 dias. Para realização da pesquisa, fez-se uso da resolução de bioética número 714 do Conselho Nacional de Medicina Veterinária ${ }^{16}$, sendo o projeto registrado na Comissão de Ética em Pesquisa com Animais de Experimentação (CEPAE) da Universidade Federal do Pará sob número de protocolo 207-14.

Utilizou-se um delineamento inteiramente casualizado, com cinco tratamentos e quatro repetições, ou seja, diferentes fotoperíodos (0L:24E; 6L:18E; 12L:12E; 18L:6E; 24L:0E), em que $\mathrm{L}$ corresponde ao período de luz e $\mathrm{E}$ ao de escuro. Foram utilizados 160 alevinos de tilápia do Nilo com peso e comprimento iniciais de 3,21 \pm $0,05 \mathrm{~g} \mathrm{e} 4,35 \pm 0,07 \mathrm{~cm}$, respectivamente, que foram distribuídos aleatoriamente na densidade de estocagem de oito peixes por aquário. $\mathrm{O}$ experimento foi conduzido em 20 aquários, contendo 20 litros, em sistema fechado de recirculação de água, com temperatura controlada por termostato.

Grupos de quatro aquários foram mantidos isoladamente sob sistema de iluminação controlado por temporizadores individuais e uma lâmpada fluorescente de $20 \mathrm{~W}$ com constante intensidade de 1180 lux sobre a superfície da água. De acordo com metodologia de Larson et al. ${ }^{17}$, para iluminação do ambiente externo do laboratório, foi utilizada uma lâmpada de coloração vermelha de $60 \mathrm{~W}$ que era acesa durante a alimentação, biometria e limpeza dos aquários.

Os peixes foram alimentados duas vezes ao dia, nos horários de $9 \mathrm{~h}$ e de $17 \mathrm{~h}$, com ração comercial extrusada contendo $40 \%$ de proteína bruta (garantia informada pelo fabricante) e pellets de dois a três milímetros de diâmetro. A quantidade de ração fornecida foi $5 \%$ do peso vivo durante os primeiros 15 dias e, posteriormente, $3 \%$ do peso vivo até o final do experimento. Para correção do fornecimento de ração, as biometrias foram 
realizadas em intervalos de 15 dias.

Diariamente, os seguintes parâmetros de qualidade da água foram monitorados: temperatura e oxigênio dissolvido por meio do oxímetro AT 150 - modelo ALFAKIT (Florianópolis, Santa Catarina, Brasil) e pH por meio de phmetro AT 315 - modelo ALFAKIT (Florianópolis, Santa Catarina, Brasil). A concentração de amônia foi monitorada uma vez por semana por meio de kit amônia-indotest ALFAKIT (Florianópolis, Santa Catarina, Brasil).

Ao final do experimento, os peixes foram mantidos em jejum por um período de 24 horas. Em seguida, 10 animais de cada fotoperíodo foram eutanasiados com 2-fenoxietanol $(1,0 \mathrm{~mL} / \mathrm{L})$ e amostras do filé foram retiradas e armazenadas em freezer $\left(-80{ }^{\circ} \mathrm{C}\right)$ para posteriores análises da composição centesimal. O mesmo procedimento foi adotado, antes do período experimental, com 30 alevinos de tilápia para determinação da proteína e lipídio corporal inicial do filé.

As amostras de filés foram liofilizadas para posteriormente serem trituradas. A matéria seca e umidade das amostras dos peixes e dietas experimentais foram determinadas em estufa a $105^{\circ} \mathrm{C}$ por um período de uma hora até atingir peso constante. Em seguida, foi determinada a matéria mineral, realizada pela incineração em mufla a $600{ }^{\circ} \mathrm{C}$ por quatro horas. A proteína bruta foi determinada pelo método de micro Kjeldahl e o extrato etéreo foi determinado pela extração com éter etílico por 4 horas.

Todas as metodologias foram seguidas conforme as descritas pela $\mathrm{AOAC}^{18}$.

As retenções de proteína (RPB) e de lipídio (RLIP) foram determinadas a partir das seguintes equações:

$\mathrm{RPB}(\%)=100 \mathrm{x}[($ proteína corporal final $\mathrm{x}$ peso final) - (proteína corporal inicial $\mathrm{x}$ peso inicial)]/ total de proteína ingerida

RLIP $(\%)=100 \times$ [(lipídio corporal final $\mathrm{x}$ peso final) - (lipídio corporal inicial $\mathrm{x}$ peso inicial)]/ total de lipídio ingerido

Os dados de composição centesimal e retenção de nutrientes de cada fotoperíodo foram submetidos à análise de variância $(\mathrm{P}<0,05)$. Em caso de significância, foi realizado um teste de Tukey a 5\% de probabilidade para comparação das médias entre os tratamentos com o auxílio do programa para análise estatística SISVAR $4.3{ }^{19}$.

\section{RESULTADOS E DISCUSSÃO}

Os valores médios de temperatura $(27,2 \pm$ $\left.0,99{ }^{\circ} \mathrm{C}\right), \mathrm{pH}(6,95 \pm 0,05)$, oxigênio dissolvido $(7,35 \pm 0,41 \mathrm{mg} / \mathrm{L})$ e a concentração de amônia $(0,12 \mathrm{mg} / \mathrm{L})$ estiveram dentro dos padrões préestabelecidos para a espécie.

$\mathrm{O}$ efeito da manipulação do fotoperíodo sobre a composição corporal de alevinos de tilápia do Nilo está representado na Tabela 1.

Tabela 1. Efeito do fotoperíodo sobre a composição centesimal e retenção de proteína bruta (RPB) e lipídio (RLIP) do filé de juvenis de tilápia do Nilo Oreochromis niloticus

\begin{tabular}{lccccc}
\hline \multicolumn{5}{c}{ Fotoperíodo } \\
\hline Variáveis & $0 \mathrm{~L}: 24 \mathrm{E}$ & $6 \mathrm{~L}: 18 \mathrm{E}$ & $12 \mathrm{~L}: 12 \mathrm{E}$ & $18 \mathrm{~L}: 6 \mathrm{E}$ & $24 \mathrm{~L}: 0 \mathrm{E}$ \\
\hline Umidade (\%) & $75,82 \pm 0,53^{\mathrm{a}}$ & $75,85 \pm 1,08^{\mathrm{a}}$ & $75,65 \pm 1,89^{\mathrm{a}}$ & $77,02 \pm 0,74^{\mathrm{a}}$ & $76,19 \pm 1,51^{\mathrm{a}}$ \\
Cinzas (\%) & $2,39 \pm 0,25^{\mathrm{a}}$ & $2,46^{\mathrm{a}} \pm 0,34^{\mathrm{a}}$ & $2,21^{\mathrm{a}} \pm 0,16^{\mathrm{a}}$ & $2,31^{\mathrm{a}} \pm 0,24^{\mathrm{a}}$ & $2,36^{\mathrm{a}} \pm 0,16^{\mathrm{a}}$ \\
PB (\%) & $21,57 \pm 0,58^{\mathrm{a}}$ & $22,27 \pm 0,44^{\mathrm{b}}$ & $22,74 \pm 0,51^{\mathrm{bc}}$ & $23,04 \pm 0,61^{\mathrm{c}}$ & $22,17 \pm 0,37^{\mathrm{ab}}$ \\
Lipídios (\%) & $1,31 \pm 0,14^{\mathrm{b}}$ & $1,35 \pm 0,23^{\mathrm{b}}$ & $1,24 \pm 0,24^{\mathrm{b}}$ & $0,94 \pm 0,14^{\mathrm{a}}$ & $1,35 \pm 0,20^{\mathrm{b}}$ \\
RPB (\%) & $7,57 \pm 0,20^{\mathrm{d}}$ & $8,35 \pm 0,17^{\mathrm{c}}$ & $9,39 \pm 0,21^{\mathrm{b}}$ & $9,89 \pm 0,26^{\mathrm{a}}$ & $9,36 \pm 0,16^{\mathrm{b}}$ \\
RLIP (\%) & $0,46 \pm 0,05^{\mathrm{bc}}$ & $0,51 \pm 0,09^{\mathrm{ab}}$ & $0,51 \pm 0,10^{\mathrm{ab}}$ & $0,40 \pm 0,06^{\mathrm{c}}$ & $0,57 \pm 0,08^{\mathrm{a}}$ \\
\hline
\end{tabular}

L: horas de luz; E: horas de escuro. Valores na mesma linha seguidos por letras diferentes são significativamente diferentes pelo teste de Tukey $(\mathrm{P}<0,05)$.

Não houve efeito dos diferentes fotoperíodos sobre a umidade e cinzas do filé $(\mathrm{P}>0,05)$ (Tabela 1$)$. Resultados semelhantes foram demonstrados em estudo com Pagrus major ${ }^{6}$, Oplegnathus fasciatus $^{20} \mathrm{e}$ Colossoma macropomum ${ }^{21}$, em que os percentuais de umidade e cinzas não alteraram nos peixes submetidos aos diferentes fotoperíodos. Geralmente, um aumento na concentração de lipídios proporciona uma diminuição na porcentagem de água, proteínas e cinzas na composição corporal ${ }^{22}$.

Por outro lado, a composição do filé dos peixes submetidos ao fotoperíodo de 18L:6E 
demonstraram maior quantidade de proteína e retenção desta no filé, assim como também menor quantidade de gordura e retenção de lipídio $(\mathrm{P}<0,05)$. Resultado semelhante foi demonstrado em estudo com Oplegnathus fasciatus, em que os peixes submetidos aos fotoperíodos de 16L:8E e 24L:0E apresentaram maior retenção de proteína corporal, assim como uma tendência de maior porcentagem de proteína corporal. Entretanto, não houve variação no percentual de gordura corporal dos peixes submetidos aos diferentes fotoperíodos ${ }^{20}$. Biswas et al. ${ }^{6}$, em estudo com a espécie Pagrus major, demonstraram que os peixes submetidos aos fotoperíodos de $16 \mathrm{~L}: 8 \mathrm{E}$ e 24L:0E apresentaram maior percentual de proteína corporal, enquanto que não houve diferença significativa para a retenção de proteína, assim como o percentual de gordura. No entanto, filés de juvenis de Colossoma macropomum, submetidos a diferentes fotoperíodos, não apresentaram diferença quanto à composição centesimal ${ }^{21}$.

Acredita-se que, durante esse tempo, os animais apresentaram maior concentração de proteína bruta no filé por permanecerem maior tempo, após a alimentação, expostos à luz. Segundo Biswas et al. ${ }^{6}$, ${ }^{13}$, o intervalo de tempo mais longo entre os momentos de alimentação, sob longos fotoperíodos, pode permitir um processo digestivo mais eficiente, o que reflete em uma melhor digestão e eficiência de retenção dos nutrientes. Outro fator que pode ter contribuído para a maior porcentagem de proteína bruta nos fotoperíodos longos é a maior estimulação hormonal do apetite, como por exemplo, o hormônio do crescimento, conhecido por ter um efeito orexigênico e que pode ter aumentado sua

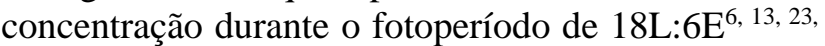
${ }^{24}$. Além disso, quando os peixes são submetidos a essas condições, o maior crescimento é provavelmente devido ao aumento da deposição de aminoácidos para a formação da proteína corporal. Isso pode ser atribuído ao fato de as proteínas corporais serem as responsáveis pela maior parte do crescimento em termos de ganho de peso ${ }^{6}$.

Os animais submetidos ao fotoperíodo de 12L:12E apresentaram valores intermediários de proteína no filé em relação aos peixes submetidos aos períodos de 18L:6E e de $6 \mathrm{~L}: 18 \mathrm{E}(\mathrm{P}<0,05)$. Os peixes sob o fotoperíodo de $0 \mathrm{~L}: 24 \mathrm{E}$ apresentaram os menores níveis de proteína no filé $(\mathrm{P}<0,05)$ (Tabela 1). Esse resultado pode estar atribuído à ineficácia dos processos digestivos e assimilação dos nutrientes nessas condições, uma vez que se trata de uma espécie diurna.

A quantidade de gordura e retenção desta foi menor no fotoperíodo de 18L:6E $(\mathrm{P}<0,05)$. Acreditase que os peixes submetidos a esse fotoperíodo apresentaram uma maior mobilização de lipídios, necessária para compensar a elevada demanda de energia para o crescimento e para uma alta taxa metabólica. Além disso, peixes expostos a longos fotoperíodos podem apresentar baixa concentração de lipídio corporal, indicando que parte desse lipídio pode ser utilizada para mobilizar energia para suprir uma elevada demanda energética devido à maior atividade dos animais ${ }^{6,14}$

O teor de gordura possui importância na validade comercial dos produtos e é essencial para a aceitação geral pelos consumidores. Maiores teores de gordura $(5,7 \%)$ no filé da tilápia do Nilo foram encontrados por Clements e Lovell ${ }^{1}$ e por Cho e JaeYoon $^{25}$. Utiliza-se o teor de gordura como critério prático para comparações entre diferentes espécies de pescado. Considera-se pescado gordo quando o teor de lipídios mínimo é de $10 \%$, pescado semi-gordo para valores entre 2,5 a $10 \%$ e pescado magro com no máximo de 2,5\% de gordura. Dessa forma, o teor de gordura observado neste estudo permite considerar o filé de tilápias do Nilo submetidas aos diferentes fotoperíodos como produto magro.

Assim, peixes submetidos ao fotoperíodo de 18L:6E apresentam uma menor deposição de gordura nos filés da tilápia do Nilo, bem como um elevado conteúdo proteico. Provavelmente, tais características tornam este produto de maior aceitação no mercado consumidor, assim como mais atraentes para produtores e indústrias. Dessa forma, a oferta de um produto com baixo teor de gordura aumenta o rendimento de carcaça no processamento, assim como melhora a qualidade do produto final ${ }^{26}$, aumentando o prazo de validade do pescado devido à menor disponibilidade de ácidos graxos insaturados disponíveis para o processo de peroxidação lipídica.

\section{CONCLUSÃO}

O fotoperíodo pode alterar a composição corporal de juvenis de tilápia do Nilo, uma vez que influencia as taxas metabólicas de mobilização de nutrientes, principalmente na deposição de proteína e utilização da gordura corporal. Assim, o emprego do fotoperíodo de 18L:0E proporciona um peixe com maior conteúdo proteico e menor conteúdo de lipídio corporal, favorecendo o processamento na indústria, assim como a qualidade do produto final para os consumidores.

\section{AGRADECIMENTOS}

Ao Conselho Nacional de Pesquisa (CNPq), à Fundação de Amparo à Pesquisa de Minas Gerais (FAPEMIG), à Coordenação de Aperfeiçoamento de Pessoal de Nível Superior (CAPES). 


\section{REFERÊNCIAS}

1. Clements S, Lovell RT. Comparison of processing yields and nutrient composition of culture Nile tilapia (Oreochromis niloticus) and channel catfish (Ictalurus punctatus). Aquaculture [Internet]. 1994 Jan [cited 2014 Feb 26]; 119(2-3):299-310. Available from: http://www.sciencedirect.com/science/article/pii/0044848 694901848.

2. Hildsorf AWS. Genética e cultivo de tilápias vermelhas - Uma revisão [Genetics and culture of red tilápia - A review]. Boletim do Instituto de Pesca [Internet]. 1995 Jan/Jun [cited 2014 Feb 26]; 22(1):73-84. Available from: ftp://ftp.sp.gov.br/ftppesca/B_22_1_73-84.pdf.

Portuguese.

3. Furuya WM, Botaro D, Macedo RMG, Santos VG, Silva LCR, Silva TC, Furuya VRB, Sales PJ P. Aplicação do conceito de proteína ideal para redução dos níveis de proteína em dietas para tilápia-do-nilo (Oreochromis niloticus) [Ideal protein concept for dietary protein reduction of juvenile Nile tilapia (Oreochromis niloticus)]. Revista Brasileira de Zootecnia [Internet]. 2005 Set/Out [cited 2014 Feb 26]; 34(5):143-1441. Available from: http://www.scielo.br/pdf/rbz/v34n5/26622.pdf.

Portuguese.

4. Leonhardt JH, Filho MC, Frossard H, Moreno AM. Características morfométricas, rendimento e composição do filé de tilápia do Nilo, Oreochromis niloticus, da linhagem tailandesa, local e do cruzamento de ambas [Morphometrics, fillet yield and fillet composition in Nile tilapia, Oreochromis niloticus, strains thai chitralada, Brazil local and their hybrid]. Semina: Ciências Agrárias [Internet]. 2006 Jan/Mar, [cited 2014 Feb 26]; 27(1):125132. Available from: http://dx.doi.org/10.5433/1679$\underline{0359.2006 \mathrm{v} 27 \mathrm{n} 1 \mathrm{p} 125}$

5. Garduño-Lugo M, Granados-Alvarez I, Olivera-Novoa M, Muñoz-Córdova G. Comparison of growth, fillet yield and proximate composition between Stirling Nile tilapia (wild type) (Oreochromis niloticus, Linnaeus) and red hybrid tilapia (Florida red tilapia X Stirling red $O$. Niloticus) males. Aquaculture Research [Internet]. 2003 Sep [cited 2014 Feb 26]; 34(12):1023- 1028. Available from: http://onlinelibrary.wiley.com/doi/10.1046/j.13652109.2003.00904.x/abstract.

6. Biswas AK, Seoka M, Inoue Y, Takii K, Kumai H. Photoperiod influences the growth, food intake, feed efficiency and digestibility of red sea bream (Pagrus major). Aquaculture [Internet]. 2005 Dec [cited 2014 Feb 26]; 250(3-4):666-673. Available from: http://www.sciencedirect.com/science/article/pii/S004484 $\underline{8605003017 .}$

7. Biswas AK, Takeuchi T. Effects of different photoperiod cycles on metabolic rate and energy loss of both fed and unfed adult tilapia Oreochromis niloticus: part II. Fisheries Science [Internet]. 2002 Jun [cited 2014 Feb 26]; 68(3):543-553. Available from: http://onlinelibrary.wiley.com/doi/10.1046/j.1444- 2906.2002.00460.x/abstract.

8. Reynalte-Tataje D, Luz, RK, Meurer S, Zaniboni-Filho E, Nuñer APO. Influência do fotoperíodo no crescimento e sobrevivência de pós-larvas de piracanjuba Brycon orbignyanus (Valenciennes, 1849) (Osteichthyes, Characidae) [Influence of photoperiod on the growth and survival of piranjuba post-larvae Brycon orbignyanus (Valenciennes, 1849) (Osteichthyes, Characidae)]. Acta Scientiarum [Internet]. 2002 [cited 2014 Feb 26]; 24(2):439-443. Available from: http://dx.doi.org/10.4025/actascibiolsci.v24i0.2317. Portuguese.

9. Boeuf G, Le Bail, PY L. Does light have an influence on fish growth? Aquaculture [Internet]. 1999 Jul [cited 2014 Feb 26]; 177(1-4):129-152. Available from: http://www.sciencedirect.com/science/article/pii/S004484 $\underline{8699000745}$.

10. Veras GC, Murgas LDS, Rosa, PV, Zangeronimo MG, Ferreira MSS, Solis-de Leon, JÁ. Effect of photoperiod on locomotor activity, growth, feed efficiency, and gonadal development of Nile tilapia. Revista Brasileira de Zootecnia [Internet]. 2013 [cited 2014 Feb 26]; 42 (12): 844-849. Available from: http://www.scielo.br/pdf/rbz/v42n12/02.pdf.

11. Veras GC, Murgas LDS, Zangeronimo MG, Oliveira MM, Rosa PV, Felizardo VO. Ritmos biológicos e fotoperíodo em peixes. Archivos de Zootecnia [Internet]. 2013 [cited 2014 Feb 26]; 62(R): 25-43. Available from: http://www.uco.es/organiza/servicios/publica/az/php/img/ web/12_11_03_2725REVISIONRitmosVera.pdf.

12. Veras GC, Murgas LDS, Zangernimo MG, Rosa PV, Solis-de Leon JA, Salaro AL. Fotoperíodo sobre parâmetros fisiológicos relacionados ao estresse em alevinos de tilápia-do-nilo. Arquivo Brasileiro de Medicina Veterinária e Zootecnia [Internet]. 2013 [cited 2014 Feb 26]; 65(5): 1434-1440. Available from: http://www.scielo.br/pdf/abmvz/v65n5/a23v65n5.pdf.

13. Biswas AK, Seoka M, Tanaka Y, Takii K, Kumai H. Effect of photoperiod manipulation on the growth performance and stress response of juvenile red sea bream (Pagrus major). Aquaculture [Internet]. 2006 Aug [cited 2014 Feb 26]; 258(1-4):350-356, 2006. Available from: http://www.sciencedirect.com/science/article/pii/S004484 $\underline{8606002493}$.

14. Ginés R, Afonso JM, Argüello A, Zamorano MJ, Lopez JL. Growth in adult gilthead sea bream (Sparus aurata L.) as a result of interference in sexual maturation by different photoperiod regimes. Aquaculture Research [Internet]. 2003 Jan [cited 2014 Feb 26]; 34(1):73-78. Available from: http://onlinelibrary.wiley.com/doi/10.1046/j.13652109.2003.00801.x/abstract.

15. Rad F, Bozaoğlu S, Gözükara SE, Karahan A, Kurt G. Effects of different long-day photoperiods on somatic growth and gonadal development in Nile tilapia (Oreochromis niloticus L.) Aquaculture [Internet]. 2006 May [cited 2014 Feb 26]; 255(1-4):292-300. Available from: 
http://www.sciencedirect.com/science/article/pii/S004484 8605007283.

16. Conselho Federal de Medicina Veterinária do Brasil. Resolução CFMV no 714, de 20 de junho de 2002. Disponível em: http://www.cfmv.org.br/portal/legislacao/resolucoes/resol ucao_714.pdf.

17. Larson ET, Winberg S, Mayer I, Lepage O, Summers $\mathrm{CH}$, Øverli Ø. Social stress affects circulating melatonin levels in rainbow trout. General and Comparative Endocrinology [Internet] 2004 May [cited 2014 Feb 26]; 136(3):322-327. Available from: http://www.sciencedirect.com/science/article/pii/S001664 $\underline{8004000073 .}$.

18. AOAC International. Official Methods of Analysis of the AOAC International. 16th ed. Arlington: AOAC International, 1990. 1141p.

19. Ferreira DF. Sisvar: a computer statistical analysis system. Ciência e Agrotecnologia [Internet]. 2011 Nov/Dec [cited 2014 Feb 26]; 35 (6):1039-1042. Available from: http://www.scielo.br/pdf/cagro/v35n6/a01v35n6.pdf.

20. Biswas AK, Seoka M, Ueno K, Yong ASK, Biswas BK, Kim YS, Takii K, Kumai H. Growth performance and physiological responses in striped knifejaw, Oplegnathus fasciatus, held under diferrent photoperiods. Aquaculture [Internet]. 2008 Jul [cited 2014 Feb 26]; 279(1-4):42-46. Available from: http://www.sciencedirect.com/science/article/pii/S004484 8608002858 .

21. Mendonça PP, Dos Santos MVB, Vidal Junior MV, Andrade DR. Influência do fotoperíodo emeral sobre características bromatológicas da carcaça de juvenis de tambaqui (Colossoma macropomum) [influence of ahemeral photoperiod on bromatological characteristics of carcasses of tambaqui (Colossoma macropomum) juveniles]. Ciência Animal Brasileira [Internet]. 2011 Abr/Jun [cited 2014 Feb 26]; 12(2):213-220. Available from:

http://www.revistas.ufg.br/index.php/vet/article/view/491 7/9219. Portuguese.
22. Garling DL, Wilson RP. Optimum dietary proteintoenergy ratios for channel catfish fingerlings, Ictalurus punctatus. Journal of Nutrition [Internet]. 1976 Mar [cited 2014 Feb 26]; 106:1368-1375. Available from: http://jn.nutrition.org/content/106/9/1368.full.pdf.

23. Johnsson JI, Björnsson BT. Growth hormone increases growth rate, appetite and dominance in juvenile rainbow trout, Oncorhynchus mykiss. Animal Behavior [Internet]. 1994 Jul [cited 2014 Feb 26]; 48(1):177-186. Available from:

http://www.sciencedirect.com/science/article/pii/S000334 7284712243.

24. Mccormick SD, Björnsson BT, Sheridan M, Eilerlson C, Carey JB, O'Dea M. Increased day length stimulates plasma growth hormone and gill $\mathrm{Na}+\mathrm{K}+$-ATPase in Atlantic salmon (Salmo salar). Journal of Comparative Physiology B [Internet]. 1995 Mar [cited 2014 Feb 26]; 165(4):245-254. Available from: http://link.springer.com/article/10.1007\%2FBF00367308\# page-1.

25. Cho SH, Jae-Yoon JO. Effects of dietary energy level and number of meals on growth and body composition of Nile tilapia, Oreochromis niloticus L. during summer and winter seasons. Journal of the World Aquaculture Society [Internet]. 2002 Mar [cited 2014 Feb 26]; 33(1):48-56. Available from:

http://onlinelibrary.wiley.com/doi/10.1111/j.17497345.2002.tb00477.x/abstract.

26. Arbeláez-Rojas GA, Fracalossi DM, Fim J D I. Composição corporal de tambaqui, Colossoma macropomum, e matrinxã, Brycon cephalus, em sistemas de cultivo intensivo, em Igarapé, e semi-intensivo, em viveiros [Body Composition of Tambaqui, Colossoma macropomum, and Matrinxã, Brycon cephalus, When Raised in Intensive (Igarapé Channel) and Semi-Intensive (Pond) Culture Systems]. Revista Brasileira de Zootecnia [Internet]. 2002 Jun [cited $2014 \mathrm{Feb} 26$ ]; 31(3): 1059-1069. Available from:

http://www.scielo.br/pdf/rbz/v31n3/13056.pdf.

Portuguese. 